\title{
Emergence of Triazole Resistance in Aspergillus spp. in Latin America
}

\author{
Daiana Macedo $^{1,2} \cdot$ Florencia Leonardelli $^{2}$ - Soledad Gamarra ${ }^{2} \cdot$ Guillermo Garcia-Effron $^{1,2}$ \\ Accepted: 15 April 2021 / Published online: 19 May 2021 \\ (C) The Author(s), under exclusive licence to Springer Science+Business Media, LLC, part of Springer Nature 2021
}

\begin{abstract}
Purpose of Review Azole resistance in Aspergillus spp. is becoming a public health problem worldwide. However, data about this subject is lacking in Latin American countries. This review focuses in the epidemiology and molecular mechanisms of azole resistance in Aspergillus spp. emphasizing in Latin America. Data on Aspergillus fumigatus stands out because it is the most prevalent Aspergillus spp. pathogen.

Recent Findings Azole resistance in Aspergillus spp. emergence was linked with intensive use of these antifungals both in the clinical setting and in the environment (as pesticides). Reports on azole-resistant A. fumigatus strains are being constantly published in different countries. Molecular mechanisms of resistance mainly involve substitution in the azole target (CYP51A) and/or overexpression of this gene. However, several other non-CYP51A-related mechanisms were described. Moreover, intrinsically resistant cryptic Aspergillus species are starting to be reported as human pathogens.

Summary After a comprehensive literature review, it is clear that azole resistance in Aspergillus spp. is emerging in Latin America and perhaps it is underestimated. All the main molecular mechanisms of azole resistance were described in patients and/or environmental samples. Moreover, one of the molecular mechanisms was described only in South America. Cryptic intrinsic azole-resistant species are also described.
\end{abstract}

Keywords Aspergillus $\cdot$ Triazole $\cdot$ Resistance $\cdot$ Latin America

\section{Introduction: An Overview of Aspergillosis: Clinical Aspects, Importance, Prevalence, and Treatment Options}

Aspergillosis is a group of opportunistic, heterogeneous, and non-contagious mycoses that have in common their causative agent, the species of the genus Aspergillus. These molds are saprophytic fungi that participate in the recycling of carbon and nitrogen. Their hydrophobic conidia can disperse and survive in different environments $[1 \bullet \cdot, 2]$. This genus includes more than 200 species, of which only some are human pathogens causing a diverse group of mycoses named aspergillosis

This article is part of the Topical Collection on Clinical Mycology Lab

Guillermo Garcia-Effron

ggarcia@unl.edu.ar

1 Consejo Nacional de Investigaciones Científicas y Tecnológicas, Santa Fe, Argentina

2 Laboratorio de Micología y Diagnóstico Molecular, Cátedra de Parasitología y Micología, Facultad de Bioquímica y Ciencias Biológicas, Universidad Nacional del Litoral, Santa Fe, Argentina
[3・•]. The main agents of human aspergillosis are A. fumigatus, followed by A. flavus, A. terreus, A. niger, and A. nidulans $[4,5]$. Recently, the spectrum of human pathogens within the genus was spanned including the so-called cryptic species of the sections Fumigati, Flavi, Terrei, and Nigri [3••, 6-8]. Despite this apparent diversity of causative agents, more than $70 \%$ of invasive aspergillosis is caused by A. fumigatus.

There are different clinical forms of aspergillosis and its presentation and importance depends, fundamentally, on factors related to the host. The most benign forms of infection are observed in immunocompetent patients, and the most severe forms with a worse prognosis, such as invasive aspergillosis and disseminated aspergillosis, occur in immunosuppressed patients. Other important groups of patients at risk of suffering aspergillosis are patients with chronic obstructive pulmonary diseases (especially cystic fibrosis patients and asthma) [4, 9-11]. A newer group of patients at risk of aspergillosis are severely ill Covid-19 and influenza patients (8-20\% of the ICU admitted have co-infections with this viral pathogens) $[12,13 \cdot 14]$.

The estimation of the burden of aspergillosis is difficult since these infections are not in the list of notifiable diseases 
in almost any country. However, a relatively good estimation can be made considering that the attack rate of Aspergillus spp. (invasive infections) in hematological population is at least $10 \%$. Thus, considering only the worldwide cases of acute myeloid leukemia (around 120.000 new cases in 2017), a conservative estimation would be 12,000 , but the real burden is higher since other type of patients are at risk [15-17].

The treatment options of these mycoses are limited. The 2016 ISDA practice guidelines for diagnosis and management of aspergillosis recommended triazoles as the preferred agent for treatment of invasive aspergillosis. Within these group of azoles, voriconazole (VRC) is recommended as the primary antifungal treatment. However, other triazoles as itraconazole (ITC), posaconazole (PSC), and isavuconazole (ISA) are also recommended [18••].

\section{Known Molecular Mechanisms of Triazole Resistance in Aspergillus spp.}

As with other microorganisms, resistance of filamentous fungi to antifungals is a broad concept that can be classified into clinical resistance and microbiological resistance. Microbiological resistance depends on the particular characteristics of the microorganism. The results obtained in the in vitro susceptibility tests to antifungals give an idea of this resistance. It that can be subdivided into (i) intrinsic resistance, which is that exhibited by all strains of the same species of a fungus and is not related to exposure to the antifungal, as in Aspergillus spp. and its resistance to fluconazole and (ii) secondary or acquired resistance, which is defined as the loss of activity of an antifungal agent that was once effective against a particular organism. These resistances develop after exposure to antifungal agents and are related to stable phenotypic and genotypic alterations. Azole resistance in Aspergillus spp. is an increasing worldwide problem and it is emerging in South America [19].

Azole antifungals target fungal sterol 14-demethylases, key enzymes in the biosynthetic pathway of ergosterol. These enzymes are encoded in Aspergillus spp. by two paralog genes named CYP51A and CYP51B [20•0]. Molecular mechanisms of triazole resistance in Aspergillus spp. can be crowded into to two groups named CYP51A-related resistance and nonCYP51A-related resistance [21 $]$. Intrinsic fluconazole resistance is a common characteristic for all Aspergillus spp. and it was linked exclusively with CYP51A-related mechanism (More details below) [22•]. Other triazole intrinsic resistance is seen in some of the cryptic species of the section Fumigati, Flavi, and Terrei [18••, 23-25]. As an example, A. lentulus (cryptic Fumigati species) intrinsic triazole resistance was also linked with CYP51A sequence [26]. Turning to the secondary triazole resistance mechanisms, both CYP51A related and
non-CYP51A related were described. However, the first group of mechanisms is the most prevalent worldwide [19, 21•]. In the following points of this review, we will be focusing on the particular mechanisms of azole resistance in Aspergillus spp. but as a partial conclusion, we can state that both intrinsic and secondary triazole resistance can be explained by similar molecular mechanism mostly linked with CYP51A substitutions.

\section{Mechanisms of Intrinsic Resistance in Aspergillus spp.}

All Aspergillus spp. are intrinsically resistant to fluconazole (FLC). The mechanism underlying this phenotype has been molecularly studied in A. fumigatus. This phenotype is related to a single nucleotide polymorphism in CYP51A sequence. A natural polymorphism at residue 301 isoleucine (I301) in A. fumigatus Cyp51Ap was confirmed to be implicated in it FLC-resistance since when its substitution by threonine (I301T) led to a 32-fold decrease in FLC MIC [22•]. This residue is a threonine in FLC susceptible wild type Candida albicans (T315 at Erg11p) and alanine (T315A) in FLC resistant strains (acquired resistance) [27, 28].

Non-A. fumigatus Aspergillus species may exhibit primary resistance to other antifungal drugs currently used for treatment and prophylaxis of aspergillosis, as they show high minimal inhibitory concentrations (MICs) when compared to A. fumigatus [18••, 23-25]. Sibling species of A. fumigatus in section Fumigati may be intrinsically resistant to one or more antifungals. High MIC values for amphotericin B (AMB) and azoles are being reported for A. fumigatiaffinis, A. viridinutans, and $A$. pseudofischeri, while A. udagawae shows reduced susceptibility to AMB and VRC. A. lentulus is referred as a multidrug-resistant species as all the strains of this species exhibit AMB, azole, and echinocandin reduced susceptibility [24, 25, 29-31]. The implicated mechanism of azole resistance in this species was strictly linked with its CYP51A gene sequence since when its CYP51A was transformed into an A. fumigatus strain, the recipient strain mimicked exactly the triazole resistance phenotype of A. lentulus [26].

Primary AMB resistance was described in species of the section Terrei, and it was supported by clinical and animal studies. A. terreus and cryptic species such as A. citrinoterreus, A. hortai, and A. alabamensis exhibit high AMB MICs, but are susceptible to azoles [32-34]. AMB resistance has been associated with stress response pathways, increased catalase production, and low membrane ergosterol content [35]. Sections Flavi and Nidulantes also show reduced susceptibility to AMB [36-39]. Cases of treatment failure have been reported with this polyene against $A$. flavus and its cryptic species, A. alliaceus [40].

A. niger sensu stricto and A. tubingensis (section Nigri) exhibit variable susceptibility patterns, with reduced susceptibilities to azoles [41-43]. Finally, multidrug-resistance is 
exhibited by the species of the section Usti. A. ustus and A. calidoustus are intrinsically resistant to the triazoles; they show high MIC values for AMB and variable results when tested against caspofungin [43, 44]. Molecular mechanisms underlying these susceptibility profiles in particular remain unknown.

\section{Mechanisms of Secondary Resistance in A. fumigatus and in Other Aspergillus spp.}

A. fumigatus is normally susceptible to azoles drugs; however, since the first case of azole-resistance in 1997, secondary resistance has been increasingly reported around the world, becoming a worldwide problem [19]. The development of this type of resistance occurs after azole exposure in two possible ways named the patient and the environmental route. The patient route involves the selection of resistant strains after long-term azole treatment in patients with aspergillosis. The environmental route is related to azole-resistant $A$. fumigatus selected after exposure to azole antifungals used in agriculture [19]. As described earlier, the mechanisms of azole resistance in A. fumigatus can be divided into two main groups of mechanisms, those related with CYP51A alterations (CYP51A dependent) and those related with other genes (CYP51A independent).

The most prevalent azole resistance mechanisms in A. fumigatus involve mutations in the CYP51A gene, which encode the protein $14 \alpha$ sterol demethylase, the target of azole drugs [45]. Mutations in CYP51A gene include singlenucleotide polymorphisms (SNPs), tandem repeats in the promoter, or both. The SNPs at the Cyp51Ap that affect the affinity of the enzyme to azoles are mostly located close to the opening of one of the two ligand access channels of the protein [46]. The most frequent SNPs are those involving the residues G54, G138, G448, and M220, associated with crossresistance to ITC and POS, resistance to ITC and VRC, VRC resistance, and different patterns of triazole resistance, respectively [21•]. Other less common SNPs, such as P216L, F219C, F219I, A284T, Y431C, G432S, and G434C, have also been occasionally reported related to azole resistance [47]. All of these point mutations are generally described in strains isolated from patients that have been undergoing azole treatment $[48,49]$. These mutations were grouped based on their location in three regions named hot spot 1 (includes G54 and G138), hot spot 2 (P216, F219, and M220), and hot spot 3 (Y431, G432, and G434) [21•] (Fig. 1).

The other group of CYP51A mutations are the tandem repeats in the promoter, which lead to overexpression of the gene and the subsequent development of pan-azole resistance. Tandem repeats of 34 and $46 \mathrm{bp}$ are the most frequently reported and consists in duplications of 34 and $46 \mathrm{bp}$ in the CYP51A promoter, respectively [21•]. The TR34 is always in combination with the L98H substitution conferring high level of resistance to ITC and elevated MIC values to the other triazoles [50], while TR46 has been found together with the Y121F/T289A substitutions in isolates highly resistant to VRC with simultaneous increase of azole MIC [51]. Both tandem repeated promoter sequences and both amino acid substitutions (L98H and Y121F/T289A) alone do not alter the MIC values. These facts were molecularly confirmed [50, 51] (Fig. 1). In addition, a 53-bp repeat has been found in isolates that show cross-resistance to VRC and ITC, without any other alterations in Cyp51Ap [52]. Recently, a novel combination of CYP51A mutations was reported in A. fumigatus isolated from an Argentinian cystic fibrosis patient. This newly described mutation combination consists of TR34-R65KL98H and confers pan-azole resistance [53]. These resistance mechanisms involving tandem repeats at CYP51A gene $5^{\prime}$ UTR or promoter are mainly found in environmental A. fumigatus strains [54-58] (Fig. 1).

On the other hand, a few CYP51A-independent mechanisms have been reported in A. fumigatus to contribute to clinical azole resistance, including overexpression of efflux pumps, CYP51B overexpression, cholesterol import, HapE mutations, and mutations in 3-hydroxy-3-methylglutaryl-coenzyme A (HMG-CoA) reductase-encoding gene, $H M G 1$. Among them, the most important is the overexpression of efflux pumps, specifically $\mathrm{ABC}$ and MFS transporters, associated with azole resistance by reduction of intracellular concentration of azoles [59-61]. CYP51Bmediated azole resistance is rare, as for October 2020, only one study reported a clinical azole-resistant isolate showing an overexpression of CYP51B [60]. Another described mechanism is the overexpression of SrbA, a sterolregulatory element binding protein that increases FLC and VRC resistance by CYP51A upregulation [62,63]. Also, it was seen that after azole exposure, a P88L substitution in the HapE, a CCAAT-binding transcription factor, confers resistance to azoles. This has been described as another resistance mechanism and was molecularly proven [64]. One of the latest described molecular mechanisms of azole resistance in A. fumigatus is the presence of mutations at the $H M G 1$ gene that encodes an enzyme that participate in the earlier steps (pre-squalene) of ergosterol biosynthesis $[65 \bullet \cdot]$.

Regarding non-fumigatus species, reports identifying mechanism of secondary azole resistance are limited. As in A. fumigatus, most of these reports described substitutions in Cyp51 proteins. Such is the case of A. flavus and the Y319H substitution in the Cyp51C protein [66] and several other substitutions in its Cyp51A and Cyp51B proteins [67]. In the same way, the linkage between A. lentulus azole resistance and its CYP51A was molecularly demonstrated [26] together with other single substitutions at $A$. terreus, A. niger, and $A$. tubingensis Cyp51A [21•]. 


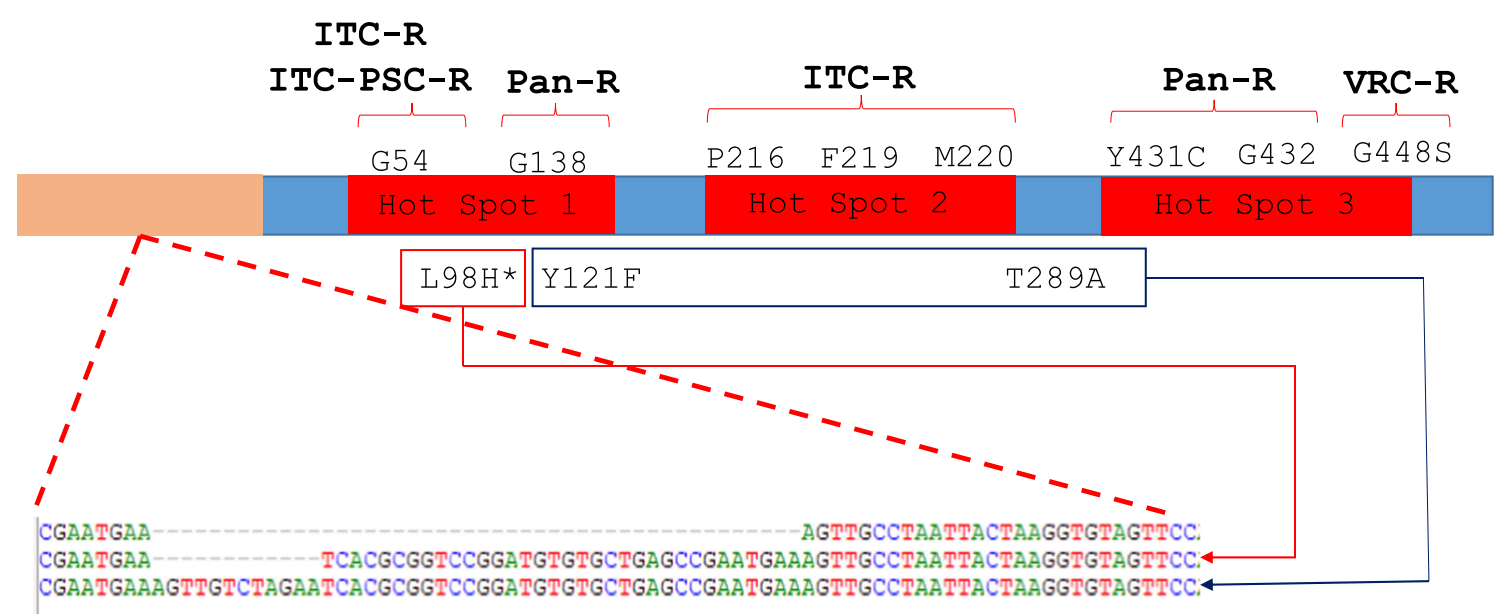

Fig. 1 CYP51A-related azole resistance mechanisms. The named hot spots are based on the names suggested by Dudakova et al. (ref). ITC, itraconazole; PSC, posaconazole; VRC, voriconazole; Pan-R, pan-azole resistance; ITC-R, resistance to itraconazole alone; ITC-PSC-R, cross itraconazole-posaconazole resistance; VRC-R, voriconazole resistance. *L98H was described to be either alone or together with other substitutions

fibrosis patients) $[72,73]$. In addition, differences on the diagnostics have to be taken into account. Some health professionals rely on non-culture-based tools (mainly galactomannan detection) for invasive aspergillosis diagnostics. Thus, no culture is obtained, and as a consequence, no resistance prevalence can be determined [74]. The conclusions obtained from published reports on this topic depend on where the study was carried out and ranged from considering that resistance is a serious problem to that it is a minimal or emerging problem. Most report from clinical setting in Europe stated the first idea. In two hospitals from Germany, resistant A. fumigatus strains were isolated in $29.6 \%$ of the hematopoietic stem cell transplantation patients [75], while in the UK, prevalence was similar (28\%) [76]. Similarly, $>20 \%$ resistance was described in the Netherlands in high-risk patients [77], whereas in Spanish [78] and Dutch [79] general population, this prevalence seems to be as low as $1.8 \%$ and $4 \%$, respectively. On the other hand, in other continents, azole resistance prevalence in high-risk patients was lower: $1.7 \%$ in India [80], $0.6-11.8 \%$ in the USA $[69,81], 2.6 \%$ in Australia [82], and $1.8 \%$ in Brazil [83]. These differences in azole resistance frequencies can be skewed due to studied populations, center complexity, and even partly due to the used denominator. Moreover, azole treatment seems to have little influence in the resistance development since most resistance is believed to be acquired in the environment (-TR-mediated resistance) and azole-naïve patients may be infected by a resistant isolate. Taking this panorama into account, Dutch experts recommended to established the local resistance rates (hospital and environmental) and use the standard empirical treatment (VRC) if the resistance rate is lower than $10 \%$. If this prevalence is higher, VRC treatment should be revised [84].

Azole resistance prevalence seems to be high in cystic fibrosis patients due to the extensive use of azole antifungals. In 
a French cohort, $20 \%$ of the cystic fibrosis exposed to ITC showed azole-resistant $A$. fumigatus in their sputum samples [85], while in Argentina, this percentage was 8\% [72], and in Germany, resistant strains were isolated in $2.71 \%$ of the patients (TR34/L98H allele was the most frequent followed by M220L and TR46/Y121F/T289A) [73].

\section{Epidemiology of Triazole Resistance in A. fumigatus in Latin American Countries}

As in other continents, reporting of fungal diseases in Latin America is not mandatory. As for October 2020, there are no reports of triazole resistance published in www.pubmed.gov from Bolivia, Chile, Ecuador, Guyana, Paraguay, and Uruguay. Thus the following paragraphs will include data limited to Argentinian, Brazilian, Colombian, and Peruvian reports (Fig. 2)

In Argentina, three retrospective surveys on fungal infections were conducted in 2004, 2008, and 2010, and one prospective surveillance between 2010 and 2012 [86, 87]. Moreover, in 2018, invasive aspergillosis and chronic pulmonary and allergic bronchopulmonary aspergillosis rates were calculated [88]. All studies agreed that A. fumigatus is the most predominant species causing invasive mold disease. Susceptibility testing of the isolates showed low azole MIC values [86, 87]. In a 2011 study, 23 isolates of the section Fumigati were characterized and three were ITC resistant (MIC $>16 \mu \mathrm{g} / \mathrm{ml}$ ), but no further characterization was done [89]. In a report published in 2019, an $8.1 \%$ ITC resistance rate was described in a single Argentinian institution [90•]. However, no nationwide epidemiology studies on antifungal resistance in clinical settings were carried out. Yet, some specific case reports were published. In 2017, the first A. fumigatus strain harboring a G54E substitution (ITC MIC $>16 \mu \mathrm{g} / \mathrm{ml}$ ) in
Latin America was reported in corneal lesion produced by an accidental inoculation of a vegetal detritus of the azole naive patient. This patient was treated with natamycin drops resolving the infection [91]. In 2018, the first South American isolate harboring a TR46/Y121F/T289A allele was described. This strain in particular was isolated in 2009 but reported in 2018. It was isolated from a brain biopsy in an acute lymphoblastic leukemia patient. Microbiological cure was achieved after the recuperation of the patient's immune status and antifungal treatment with AMB combined with caspofungin and ITC [92]. Finally, it was recently reported a case where three different $A$. fumigatus strains were isolated from a cystic fibrosis patient receiving long-term triazole therapy. Strains harbored the resistance allele TR34L98H-S297T, which confers pan-azole resistance. In addition, one of the strains also carried a $\mathrm{R} 65 \mathrm{~K}$ substitution in Cyp51Ap. This new mutation was confirmed to increase MIC values for all triazoles [53]. These strains were reported again as part of a study designed to report the incidence of triazole resistance in cystic fibrosis patients in Argentina [72]. In a recent report, triazole resistance in A. flavus was reported in clinical and environmental Argentinian strains linked with CYP51C mutations [93].

Reports on triazole resistance in Aspergillus spp. from Brazil are scarce. Negri et al. affirmed in 2017 that azole resistance was not emerging in Brazil, but these authors reported under that statement that they found $1.8 \%$ of the A. fumigatus isolated from invasive aspergillosis have VRC MICs above the epidemiological cut off values [83].

In a prospective descriptive study performed in 2019 which includes 143 A. fumigatus sensu stricto strains isolated in two tertiary hospital from Peru, triazole resistance prevalence was $2.09 \%(n=3)$. The isolates harbored different mutations including M220K, G54E, and TR34-L98H. The resistant strains were isolated from patients diagnosed
Fig. 2 Distribution of the described azole resistant strains in South America

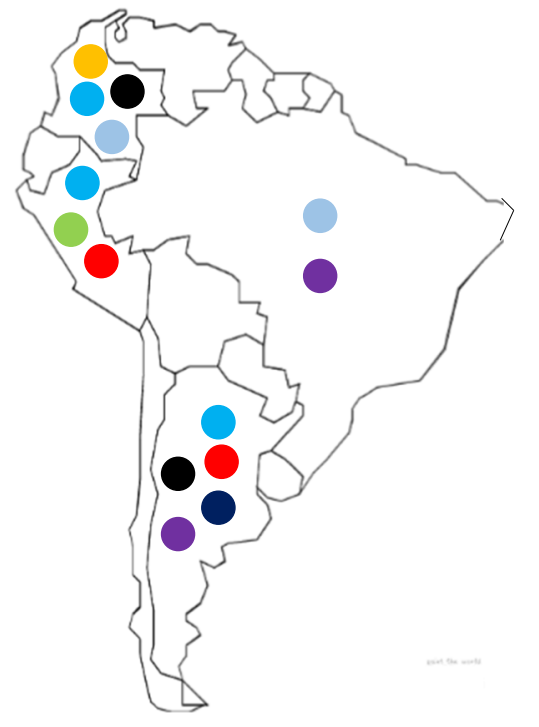

G54E

M220K

TR34-L98H

TR34/R65K/L98H

TR46/Y121F/T289A

TR53

Non-CYP51 related

Cryptic intrinsic resistant species 
Table 1 Molecular mechanisms of azole resistant in A. fumigatus described in South America

\begin{tabular}{|c|c|c|c|c|c|c|c|c|c|}
\hline \multirow{2}{*}{$\begin{array}{l}\text { Cyp51A aa. Substitutions/ } \\
\text { Cryptic specie }\end{array}$} & \multirow{2}{*}{$\begin{array}{l}\text { Country of } \\
\text { isolation }\end{array}$} & \multirow[t]{2}{*}{ Patient/origin } & \multirow[t]{2}{*}{ Sample } & \multirow[t]{2}{*}{$n$} & \multicolumn{4}{|c|}{$\mathrm{MIC}(\mu \mathrm{g} / \mathrm{ml})$} & \multirow[t]{2}{*}{ Ref } \\
\hline & & & & & ITC & VRC & PSC & ISA & \\
\hline G54E & Argentina & Azole naïve & Cornea & 1 & $>8.00$ & 0.25 & 0.12 & ND & {$[91]$} \\
\hline G54E & Peru & $\begin{array}{l}\text { Itraconazole exposure/chronic } \\
\text { pulmonary aspergillosis }\end{array}$ & $\begin{array}{l}\text { Undefined } \\
\text { respiratory } \\
\text { sample }\end{array}$ & 1 & $>16$ & 0.50 & 0.06 & ND & [101] \\
\hline M220K & Peru & $\begin{array}{l}\text { Itraconazole exposure/chronic } \\
\text { pulmonary aspergillosis }\end{array}$ & $\begin{array}{l}\text { Undefined } \\
\text { respiratory } \\
\text { sample }\end{array}$ & 1 & $>16$ & 1.00 & 1.00 & ND & [101] \\
\hline TR34-L98H & Argentina & Itraconazole/exposure Cystic fibrosis & Sputum & 2 & $>16.00$ & 8.00 & 4.00 & 4.00 & {$[53]$} \\
\hline TR34/L98H & Colombia & Flower fields & Soil & 1 & Grew $^{a}$ & $\begin{array}{l}\text { Did not } \\
\text { grew }^{\text {a }}\end{array}$ & ND & ND & {$[56]$} \\
\hline TR34/L98H & Colombia & Vegetable fields & Soil & 1 & $>8.00$ & 8.00 & ND & ND & [95] \\
\hline TR34/L98H & Peru & $\begin{array}{l}\text { Itraconazole exposure/chronic } \\
\text { pulmonary aspergillosis }\end{array}$ & $\begin{array}{l}\text { Undefined } \\
\text { respiratory } \\
\text { sample }\end{array}$ & 1 & $>16$ & 2.00 & 0.50 & ND & [101] \\
\hline TR34/L98H & Brazil & Strain collection & Sputum & 2 & $>8.00$ & 2.00 & 1.00 & ND & [100] \\
\hline TR34/R65K/L98H & Argentina & Itraconazole exposure/cystic fibrosis & Sputum & 1 & $>16.00$ & 2.00 & 1.00 & 1.00 & {$[53]$} \\
\hline TR46/Y121F/T289A & Argentina & $\begin{array}{l}\text { Voriconazole exposure/acute } \\
\text { lymphoblastic leukemia }\end{array}$ & Brain biopsy & 1 & 8.00 & $>16.00$ & 0.50 & ND & [92] \\
\hline TR46/Y121F/T289A & Colombia & Flower fields & Soil & 17 & Grew $^{a}$ & Grew $^{a}$ & ND & ND & {$[56]$} \\
\hline TR46/Y121F/T289A & Colombia & Vegetable fields & Soil & 8 & 1.00 & $>16$ & ND & ND & {$[95]$} \\
\hline TR53 & Colombia & Flower fields & Soil & 2 & Grew $^{a}$ & $\begin{array}{l}\text { Did not } \\
\text { grew }\end{array}$ & ND & $\mathrm{ND}$ & {$[56]$} \\
\hline TR53 & Colombia & Vegetable fields & Soil & 1 & $>8.00$ & 4.00 & ND & ND & {$[95]$} \\
\hline Wild type & Brazil & Strain collection & Undefined & 4 & ND & 2.00 & ND & ND & [83] \\
\hline Wild type & Colombia & Flower fields & Soil & 1 & Grew $^{a}$ & $\begin{array}{l}\text { Did not } \\
\text { grew }^{\text {a }}\end{array}$ & ND & $\mathrm{ND}$ & {$[56]$} \\
\hline A. calidoustus & Brazil & Clinical sample & Undefined & 1 & $>32$ & 4.00 & 4.00 & ND & {$[44]$} \\
\hline A. ochraceous & Brazil & Clinical sample & Undefined & 1 & 4.00 & 1.00 & 0.50 & ND & {$[44]$} \\
\hline A. thermomutatus & Brazil & Clinical sample & Undefined & 1 & 2.00 & 16.00 & 0.50 & ND & {$[44]$} \\
\hline A. lentulus & Brazil & Kidney transplantation & Respiratory & 1 & 2.00 & 4.00 & ND & ND & [99] \\
\hline A. lentulus & Argentina & Kidney transplantation & Respiratory & 1 & ND & 2.00 & ND & ND & [97] \\
\hline
\end{tabular}

$M I C$ minimal inhibitory concentration; ITC itraconazole; VRC voriconazole; $P S C$ posaconazole; ISA isavuconazole; $M C Z$ miconazole; $N D$ no data available

${ }^{a}$ No antifungal susceptibility testing assays were performed. These strains were isolated in ITC- and VRC-containing agar plates and were classified as able or not able to growth in those plates

with chronic pulmonary aspergillosis, and those harboring M220K and G54K substitutions in its Cyp51Ap were exposed to long-term ITC treatment (>300 days) [101].

In Colombia, several A. fumigatus sensu stricto strains were isolated from soil of flower fields. Authors demonstrated that all the isolated harbor promoter alterations (-TR) including 17 strains with TR46/Y121F/T289A allele, 2 strains with the TR53 promoter alteration, and 1 strain with the TR34/L98H [56]. The same data was published by the same authors 1 year later [94]. In 2019, the same group described the isolation of 18 resistant mutants in vegetable fields. Eight of the strains harbor TR46/Y121F/t289A, 1 TR34/L98H, and 1 TR53. The other 8 strains showed no CYP51A mutations but no further studies were done [95].

\section{Intrinsic-Resistant Species Distribution in Latin America (Clinical Reports and Environmental)}

Some pathogen Aspergillus cryptic species show high triazole MIC values suggesting that they are intrinsic resistant to some of these drugs [96]. The molecular confirmation of this statement was reported by Mellado et al. for A. lentulus (section Fumigati) [26]. Thus, it would be useful to know the prevalence of these species in Latin America both in the environment and in the clinical setting.

Data about this important issue in Latin America is scarce, and as for Aspergillus spp. triazole resistance, few reports were published. Using "cryptic Aspergillus" plus the name 
of the country to search in different reference data bases (Scopus, PubMed, Google Scholar), we only found papers published by Argentinian and Brazilian groups regarding cryptic species with high azole MIC values.

In Argentina, different species of the Fumigati section were isolated in clinical and environmental samples, including A. lentulus, A. udagawae, and A. fumigatiffinis. In 2009, Montenegro et al. reported the first Argentinian isolation of A. lentulus from a patient with probable invasive aspergillosis and the first Argentinian case of simultaneous infection by A. fumigatus and A. lentulus [97]. More recently, Giusiano et al. evaluated 17 soil samples from two Argentinian semidesert areas having different geological characteristics. A. fumigatus sensu stricto and A. fumigatiaffinis were the most frequent species, followed by isolates closely related to $A$. felis and A. udagawae [98].

In Brazil, an analysis of the distribution of cryptic Aspergillus spp. was done analyzing samples from $133 \mathrm{pa}-$ tients of 12 different medical centers. Only three of the several cryptic species described in this report showed high azole MIC values (one A. thermomutatus of the section Fumigati, one A. ochraceous of the section Circumdati and one A. calidoustus of the section Usti) [44] (Table 1). In 2014 in Sao Paulo, a kidney transplant patient was diagnosed with a pulmonary invasive aspergillosis due to a A. lentulus strain showing high azole MICs [99](Table 1).

\section{Conclusions and Research Gaps}

After analyzing the data presented in this review, it is clear that azole resistance is emerging in Latin America and that it is an issue that needs to be extensively studied. Comprehensive molecular identification of clinical strains has to be performed in order to uncover the prevalence of potentially intrinsically resistant Aspergillus cryptic species in the clinical setting and in the environmental. Moreover, A. fumigatus harboring -TR resistance mechanisms linked with environmental route of resistance acquisition were described in different countries of South America. However, few data is available considering that the agriculture pesticides are increasingly used in the whole continent and prolonged azole therapies are being prescribed in South American patients.

We consider that epidemiological studies including antifungal resistance surveillance are needed in our region in order to improve patient management.

\section{Declarations}

Conflict of Interest Macedo Daiana, Leonardelli Florencia, Gamarra Soledad, and Garcia-Effron Guillermo declare that they have no conflict of interest.
Human and Animal Rights and Informed Consent This article does not contain any studies with human or animal subjects performed by any of the authors.

\section{Refereences}

Papers of particular interest, published recently, have been highlighted as:

- Of importance

• Of major importance

1.• Latgé, J.P., Chamilos, G. Aspergillus fumigatus and aspergillosis in 2019. Clin. Microbiol. Rev. 2020; 33: doi:https://doi.org/10. 1128/CMR.00140-18. A good review written by one of the most renowned researcher on Aspergillus fumigatus. It includes a comprehensive and actual description of the biological cycle; spectrum of disease, immune response, virulence, diagnostic tools and antifungal treatments. In adition new concepts are described.

2. Dagenais TRT, Keller NP. Pathogenesis of Aspergillus fumigatus in invasive aspergillosis. Clin Microbiol Rev. 2009;22:447-65.

3.• Gautier M, Normand AC, Ranque S. Previously unknown species of Aspergillus. Clin Microbiol Infect. 2016;22:662-9 Description of the cryptic species. Some of them are intrinsically resistant to different antifungal agents.

4. Denning DW. Invasive aspergillosis. Clin Infect Dis. 1998;26: 781-805. https://doi.org/10.1086/513943.

5. Morgan J, Wannemuehler KA, Marr KA, Hadley S, Kontoyiannis DP, Walsh TJ, et al. Incidence of invasive aspergillosis following hematopoietic stem cell and solid organ transplantation: interim results of a prospective multicenter surveillance program. Med Mycol. 2005;43:49-58. https://doi.org/10.1080/ 13693780400020113 .

6. Alcazar-Fuoli L, Mellado E, Alastruey-Izquierdo A, CuencaEstrella M, Rodriguez-Tudela JL. Species identification and antifungal susceptibility patterns of species belonging to Aspergillus section Nigri. Antimicrob Agents Chemother. 2009;53:4514-7. https://doi.org/10.1128/AAC.00585-09.

7. Alcazar-Fuoli L, Mellado E, Alastruey-Izquierdo A, CuencaEstrella M, Rodriguez-Tudela JL. Aspergillus section Fumigati: antifungal susceptibility patterns and sequence-based identification. Antimicrob Agents Chemother. 2008;52:1244-51. https:// doi.org/10.1128/AAC.00942-07.

8. Balajee SA, Gribskov JL, Hanley E, Nickle D, Marr KA. Aspergillus lentulus sp. nov., a new sibling species of A. fumigatus. Eukaryot. Cell. 2005;4:625-32. https://doi.org/10. 1128/EC.4.3.625-632.2005.

9. Marr KA, Patterson T, Denning D. Aspergillosis pathogenesis, clinical manifestations, and therapy. Infect Dis Clin N Am. 2002;16:875-94.

10. Latgé JP. The pathobiology of Aspergillus fumigatus. Trends Microbiol. 2001;9:382-9.

11. Buckingham SJ, Hansell DM. Aspergillus in the lung: diverse and coincident forms. Eur Radiol. 2003;13:1786-800.

12. Apostolopoulou, A., Esquer Garrigos, Z., Vijayvargiya, P., Lerner, A.H., Farmakiotis, D. Invasive pulmonary aspergillosis in patients with SARS-CoV-2 Infection: a systematic review of the literature. Diagnostics (Basel, Switzerland) 2020, 10, doi: https://doi.org/10.3390/diagnostics10100807.

13. Marr, K.A., Platt, A., Tornheim, J.A., Zhang, S.X., Datta, K., Cardozo, C., Garcia-Vidal, C. Aspergillosis complicating severe coronavirus disease. Emerg. Infect. Dis. 2020, 27, doi:https://doi. 
org/10.3201/eid2701.202896. Description of the new clinical entity linked with Aspergillus spp.

14. Borman AM, Palmer MD, Fraser M, Patterson Z, Mann C, Oliver D, et al. COVID-19 associated invasive aspergillosis: data from the UK National Mycology Reference Laboratory. J Clin Microbiol. 2020;59. https://doi.org/10.1128/JCM.02136-20.

15. Tejaswi V, Lad DP, Jindal N, Prakash G, Malhotra P, Khadwal A, et al. Chronic lymphocytic leukemia: real-world data from India. JCO Glob Oncol. 2020;6:866-72. https://doi.org/10.1200/go.20. 00032.

16. Marsà A, Ascanio M, Diaz-García J, Darbà J. Epidemiology, management, and economic impact of acute myeloid leukemia and myelodysplastic syndrome in Spain at the hospital level: a claims database analysis. J Med Econ. 2020;23:1477-84. https://doi.org/ 10.1080/13696998.2020.1840180.

17. Yi, M., Li, A. Zhou, L., Chu, Q., Song, Y., Wu, K., Wu, K. The global burden and attributable risk factor analysis of acute myeloid leukemia in 195 countries and territories from 1990 to 2017: Estimates based on the global burden of disease study 2017. J Hematol Oncol 2020, 13, doi:https://doi.org/10.1186/s13045020-00908-z.

18.•• Patterson TF, Thompson GR, Denning DW, Fishman JA, Hadley $\mathrm{S}$, Herbrecht R, et al. Practice guidelines for the diagnosis and management of aspergillosisupdate by the infectious diseases society of America. Clin Infect Dis. 2016;63:e1-e60 A complete practice guideline with data regarding with sevaral aspect of Aspergillosis diagnostics and treatment.

19. Rivero-Menendez O, Alastruey-Izquierdo A, Mellado E. CuencaEstrella, M. Triazole resistance in Aspergillus spp.: A worldwide problem? J Fungi. 2016:2.

20.• Mellado E, Diaz-Guerra TM, Cuenca-Estrella M, RodriguezTudela JL, et al. J Clin Microbiol. 2001;39:2431-8. https:/doi. org/10.1128/JCM.39.7.2431-2438.2001 With 20 years-old it is still a key work to understand how azole antifungals works in Aspergillus fumigatus.

21. Dudakova A, Spiess B, Tangwattanachuleeporn M, Sasse C, Buchheidt D, Weig M, et al. Molecular tools for the detection and deduction of azole antifungal drug resistance phenotypes in Aspergillus species. Clin Microbiol Rev. 2017;30:1065-91 A review with a description of the most common mechanisms of triazole resistance and how to detect them using molecular tools in Aspergillus spp.

22. Leonardelli F, Macedo D, Dudiuk C, Cabeza MS, Gamarra S, Garcia-Effron G. Aspergillus fumigatus intrinsic fluconazole resistance is due to the naturally occurring T301I substitution in Cyp51Ap. Antimicrob. Agents Chemother. 2016(60):5420-6. https://doi.org/10.1128/AAC.00905-16 Mechanism of intrinsic fluconazole resistance in $A$. fumigatus. It is one of the key documents that supports the clasification of A. fumigatus as intrinsically resistant to this triazole by CLSI.

23. Ullmann AJ, Aguado JM, Arikan-Akdagli S, Denning DW, Groll AH, Lagrou K, et al. Diagnosis and management of Aspergillus diseases: executive summary of the ESCMID-ECMM-ERS guideline. Clin Microbiol Infect. 2017;2018(24):e1-e38. https://doi.org/ 10.1016/j.cmi.2018.01.002.

24. Van Der Linden, J.W.M., Warris, A., Verweij, P.E. Aspergillus species intrinsically resistant to antifungal agents. In Proceedings of the Medical Mycology; Med Mycol, 2011; Vol. 49.

25. Alastruey-Izquierdo A, Alcazar-Fuoli L, Cuenca-Estrella M. Antifungal susceptibility profile of cryptic species of Aspergillus. Mycopathologia. 2014;178:427-33. https://doi.org/ 10.1007/s11046-014-9775-z.

26. Mellado E, Alcazar-Fuoli L, Cuenca-Estrella M, RodriguezTudela JL. Role of Aspergillus lentulus 14- $\alpha$ sterol demethylase (Cyp 51A) in azole drug susceptibility. Antimicrob Agents
Chemother. 2011;55:5459-68. https://doi.org/10.1128/AAC. 05178-11.

27. Morio F, Loge C, Besse B, Hennequin C, Le Pape P. Screening for amino acid substitutions in the Candida albicans Ergl1 protein of azole-susceptible and azole-resistant clinical isolates: new substitutions and a review of the literature. Diagn Microbiol Infect Dis. 2010;66:373-84. https://doi.org/10.1016/j.diagmicrobio.2009.11. 006.

28. Edlind TD, Henry KW, Metera KA, Katiyar SK. Aspergillus fumigatus CYP51 sequence: Potential basis for fluconazole resistance. Med Mycol. 2001;39:299-302. https://doi.org/10.1080/ mmy.39.3.299.302.

29. Rivero-Menendez O, Soto-Debran JC, Medina N, Lucio J, Mellado E, Alastruey-Izquierdo A. Molecular identification, antifungal susceptibility testing, and mechanisms of azole resistance in Aspergillus species received within a surveillance program on antifungal resistance in Spain. Antimicrob Agents Chemother. 2019;63. https://doi.org/10.1128/AAC.00865-19.

30. Sugui JA, Kwon-Chung KJ, Juvvadi PR, Latgé JP, Steinbach WJ. Aspergillus fumigatus and related species. Cold Spring Harb Perspect Med. 2015;5. https://doi.org/10.1101/cshperspect. a019786.

31. dos Santos RAC, Steenwyk JL, Rivero-Menendez O, Mead ME, Silva LP, Bastos RW, et al. Genomic and phenotypic heterogeneity of clinical isolates of the human pathogens Aspergillus fumigatus, Aspergillus lentulus, and Aspergillus fumigatiaffinis. Front Genet. 2020;11:459. https://doi.org/10.3389/fgene.2020. 00459 .

32. Escribano P, Peláez T, Recio S, Bouza E, Guinea J. Characterization of clinical strains of Aspergillus terreus complex: molecular identification and antifungal susceptibility to azoles and amphotericin B. Clin Microbiol Infect. 2012;18: E24-6. https://doi.org/10.1111/j.1469-0691.2011.03714.x.

33. Imbert S, Normand AC, Ranque S, Costa JM, Guitard J, Accoceberry I, et al. Species identification and in vitro antifungal susceptibility of Aspergillus terreus species complex clinical isolates from a French multicenter study. Antimicrob Agents Chemother. 2018;62:e02315-7. https://doi.org/10.1128/AAC. 02315-17.

34. Zoran T, Sartori B, Sappl L, Aigner M, Sánchez-Reus F, Rezusta A, et al. Azole-resistance in Aspergillus terreus and related species: an emerging problem or a rare phenomenon? Front Microbiol. 2018;9:516. https://doi.org/10.3389/fmicb.2018. 00516.

35. Vahedi Shahandashti R, Lass-Flörl C. Antifungal resistance in Aspergillus terreus: a current scenario. Fungal Genet Biol. 2019;131:103247.

36. Tavakoli M, Rivero-Menendez O, Abastabar M, Hedayati MT, Sabino R, Siopi M, et al. Genetic diversity and antifungal susceptibility patterns of Aspergillus nidulans complex obtained from clinical and environmental sources. Mycoses. 2020;63:78-88. https://doi.org/10.1111/myc.13019.

37. Bedin Denardi L, Hoch Dalla-Lana B, Pantella Kunz de Jesus F, Bittencourt Severo C, Morais Santurio J, Zanette RA, et al. In vitro antifungal susceptibility of clinical and environmental isolates of Aspergillus fumigatus and Aspergillus flavus in Brazil. Braz $\mathrm{J}$ Infect Dis. 2018;22:30-6. https://doi.org/10.1016/j.bjid.2017.10. 005.

38. Taghizadeh-Armaki M, Hedayati MT, Ansari S, Omran SM, Saber S, Rafati H, et al. Genetic diversity and in vitro antifungal susceptibility of 200 clinical and environmental Aspergillus flavus isolates. Antimicrob Agents Chemother. 2017;61. https://doi.org/ 10.1128/AAC.00004-17.

39. Reichert-Lima F, Lyra L, Pontes L, Moretti ML, Pham CD, Lockhart SR, et al. Surveillance for azoles resistance in Aspergillus spp. highlights a high number of amphotericin B- 
resistant isolates. Mycoses. 2018;61:360-5. https://doi.org/10. 1111/myc.12759.

40. Rudramurthy, S.M., Paul, R.A., Chakrabarti, A., Mouton, J.W., Meis, J.F. Invasive aspergillosis by Aspergillus flavus: epidemiology, diagnosis, antifungal resistance, and management. J. Fungi 2019, 5.

41. Hivary S, Fatahinia M, Halvaeezadeh M, Mahmoudabadi AZ. The potency of luliconazole against clinical and environmental Aspergillus Nigri complex. Iran J Microbiol. 2019;11:510-9.

42. Badali H, Fakhim H, Zarei F, Nabili M, Vaezi A, Poorzad N, et al. In vitro activities of five antifungal drugs against opportunistic agents of Aspergillus Nigri complex. Mycopathologia. 2016;181:235-40. https://doi.org/10.1007/s11046-015-9968-0.

43. Won EJ, Shin JH, Kim SH, Choi MJ, Byun SA, Kim MN, et al. Antifungal susceptibilities to amphotericin B, triazoles and echinocandins of 77 clinical isolates of cryptic Aspergillus species in multicenter surveillance in Korea. Med Mycol. 2018;56:501-5. https://doi.org/10.1093/mmy/myx067.

44. Negri CE, Gonçalves SS, Xafranski H, Bergamasco MD, Aquino VR, Castro PTO, et al. Cryptic and rare Aspergillus species in Brazil: prevalence in clinical samples and in vitro susceptibility to Triazoles. J Clin Microbiol. 2014;52:3633-40. https://doi.org/ 10.1128/JCM.01582-14.

45. Parker JE, Warrilow AGS, Price CL, Mullins JGL, Kelly DE, Kelly SL. Resistance to antifungals that target CYP51. J Chem Biol. 2014;7:143-61.

46. Zhang J, Li L, Lv Q, Yan L, Wang Y, Jiang Y. The fungal CYP51s: Their functions, structures, related drug resistance, and inhibitors. Front Microbiol. 2019;10:691.

47. Chowdhary A, Sharma C, Meis JF. Azole-resistant aspergillosis: Epidemiology, molecular mechanisms, and treatment. J Infect Dis. 2017;216:S436-44. https://doi.org/10.1093/infdis/jix210.

48. Howard SJ, Cerar D, Anderson MJ, Albarrag A, Fisher MC, Pasqualotto AC, et al. Frequency and evolution of azole resistance in Aspergillus fumigatus associated with treatment failure. Emerg Infect Dis. 2009;15:1068-76. https://doi.org/10.3201/eid1507. 090043

49. Garcia-Rubio R, Cuenca-Estrella M, Mellado E. Triazole resistance in Aspergillus Species: an emerging problem. Drugs. 2017;77:599-613. https://doi.org/10.1007/s40265-017-0714-4.

50. Mellado E, Garcia-Effron G, Alcázar-Fuoli L, Melchers WJG, Verweij PE, Cuenca-Estrella M, et al. A new Aspergillus fumigatus resistance mechanism conferring in vitro crossresistance to azole antifungals involves a combination of cyp51A alterations. Antimicrob Agents Chemother. 2007;51:1897-904. https://doi.org/10.1128/AAC.01092-06.

51. Van Der Linden JWM, Camps SMT, Kampinga GA, Arends JPA, Debets-Ossenkopp YJ, Haas PJA, et al. Aspergillosis due to voriconazole highly resistant Aspergillus fumigatus and recovery of genetically related resistant isolates from domiciles. Clin Infect Dis. 2013;57:513-20. https://doi.org/10.1093/cid/cit320.

52. Hodiamont CJ, Dolman KM, Ten berge IJM, Melchers WJG, Verweij PE, Pajkrt D. Multiple-azole-resistant Aspergillus fumigatus osteomyelitis in a patient with chronic granulomatous disease successfully treated with long-term oral posaconazole and surgery. Med Mycol. 2009;47:217-20. https://doi.org/10.1080/ 13693780802545600.

53. Macedo, D., Brito Devoto, T., Pola, S., Finquelievich, J.L., Cuestas, M.L., Garcia-Effron, G. A novel combination of CYP51A mutations confers pan-azole resistance in Aspergillus fumigatus. Antimicrob. Agents Chemother. 2020, 64, doi:https:// doi.org/10.1128/AAC.02501-19.

54. Moye-Rowley WS. Multiple mechanisms contribute to the development of clinically significant azole resistance in Aspergillus fumigatus. Front Microbiol. 2015;6:70.
55. Fraczek MG, Bromley M, Buied A, Moore CB, Rajendran R, Rautemaa R, et al. The cdr1B efflux transporter is associated with non-cyp51a-mediated itraconazole resistance in Aspergillus fumigatus. J Antimicrob Chemother. 2013;68:1486-96. https:// doi.org/10.1093/jac/dkt075.

56. Alvarez-Moreno C, Lavergne RA, Hagen F, Morio F, Meis JF, Le Pape P. Azole-resistant Aspergillus fumigatus harboring TR 34 /L98H, TR $46 /$ Y121F/T289A and TR 53 mutations related to flower fields in Colombia. Sci Rep. 2017;7. https://doi.org/10. 1038/srep45631.

57. Chowdhary A, Kathuria S, Xu J, Meis JF. Emergence of azoleresistant Aspergillus fumigatus strains due to agricultural azole use creates an increasing threat to human health. PLoS Pathog. 2013;9:e1003633. https://doi.org/10.1371/journal.ppat.1003633.

58. Vermeulen E, Lagrou K, Verweij PE. Azole resistance in Aspergillus fumigatus: a growing public health concern. Curr Opin Infect Dis. 2013;26:493-500.

59. Meneau I, Coste AT, Sanglard D. Identification of Aspergillus fumigatus multidrug transporter genes and their potential involvement in antifungal resistance. Med Mycol. 2016;54:616-27. https://doi.org/10.1093/mmy/myw005.

60. Buied A, Moore CB, Denning DW, Bowyer P. High-level expression of cyp $51 B$ in azole-resistant clinical Aspergillus fumigatus isolates. J Antimicrob Chemother. 2013;68:512-4. https://doi. org/10.1093/jac/dks451.

61. Hagiwara D, Miura D, Shimizu K, Paul S, Ohba A, Gonoi T, et al. A novel Zn2-Cys6 Transcription factor AtrR plays a key role in an azole resistance mechanism of Aspergillus fumigatus by coregulating cyp51A and cdr1B expressions. PLoS Pathog. 2017;13:e1006096. https://doi.org/10.1371/journal.ppat.1006096.

62. Willger SD, Puttikamonkul S, Kim KH, Burritt JB, Grahl N, Metzler LJ, et al. A sterol-regulatory element binding protein is required for cell polarity, hypoxia adaptation, azole drug resistance, and virulence in Aspergillus fumigatus. PLoS Pathog. 2008;4:e1000200. https://doi.org/10.1371/journal.ppat.1000200.

63. Blosser SJ, Cramer RA. SREBP-dependent triazole susceptibility in Aspergillus fumigatus is mediated through direct transcriptional regulation of erg11A (cyp51A). Antimicrob Agents Chemother. 2012;56:248-57. https://doi.org/10.1128/AAC.05027-11.

64. Camps SMT, Dutilh BE, Arendrup MC, Rijs AJMM, Snelders E, Huynen MA, et al. Discovery of a hapE mutation that causes azole resistance in Aspergillus fumigatus through whole genome sequencing and sexual crossing. PLoS One. 2012;7:50034. https:// doi.org/10.1371/journal.pone.0050034.

65.• Rybak, J.M., Ge, W., Wiederhold, N.P., Parker, J.E., Kelly, S.L., Rogers, P.D., Fortwendel, J.R. Mutations in $H M G 1$, challenging the paradigm of clinical triazole resistance in Aspergillus fumigatus. MBio 2019; 10, doi:10.1128/mBio.00437-19. New mechanism of triazole resistance asociated or not with CYP51A mutations.

66. Paul RA, Rudramurthy SM, Meis JF, Mouton JW, Chakrabarti A. A novel Y319H substitution in CYP51C associated with azole resistance in Aspergillus flavus. Antimicrob Agents Chemother. 2015;59:6615-9. https://doi.org/10.1128/AAC.00637-15.

67. Krishnan-Natesan S, Chandrasekar PH, Alangaden GJ, Manavathu EK. Molecular characterisation of cyp51A and cyp $51 B$ genes coding for P450 $14 \alpha$-lanosterol demethylases A (CYP51 Ap) and B (CYP51Bp) from voriconazole-resistant laboratory isolates of Aspergillus flavus. Int J Antimicrob Agents. 2008;32:519-24. https://doi.org/10.1016/j.ijantimicag.2008.06. 018 .

68. Verweij PE, Mellado E, Melchers WJG. Multiple-triazoleresistant aspergillosis [26]. N Engl J Med. 2007;356:1481-3.

69. Wiederhold NP, Gil VG, Gutierrez F, Lindner JR, Albataineh MT, McCarthy DI, et al. First detection of TR34 L98H and TR46 Y121F T289A Cyp51 mutations in Aspergillus fumigatus isolates 
in the United States. J Clin Microbiol. 2016;54:168-71. https:// doi.org/10.1128/JCM.02478-15.

70. Bader O, Weig M, Reichard U, Lugert R, Kuhns M, Christner M, et al. Cyp51A-based mechanisms of Aspergillus fumigatus azole drug resistance present in clinical samples from Germany. Antimicrob Agents Chemother. 2013;57:3513-7. https://doi.org/ 10.1128/AAC.00167-13.

71. van der Linden JWM, Arendrup MC, Warris A, Lagrou K, Pelloux H, Hauser PM, et al. Prospective multicenter international surveillance of azole resistance in Aspergillus fumigatus. Emerg Infect Dis. 2015;21:1041-4. https://doi.org/10.3201/eid2106. 140717.

72. Brito Devoto T, Hermida-Alva K, Posse G, Finquelievich JL, García-Effrón G, Cuestas ML. High prevalence of triazoleresistant Aspergillus fumigatus sensu stricto in an Argentinean cohort of patients with cystic fibrosis. Mycoses. 2020;63:93741. https://doi.org/10.1111/myc.13139.

73. Fischer J, Van Koningsbruggen-Rietschel S, Rietschel E, Vehreschild MJGT, Wisplinghoff $\mathrm{H}$, Krönke M, et al. Prevalence and molecular characterization of azole resistance in Aspergillus spp. isolates from German cystic fibrosis patients. J Antimicrob Chemother. 2014;69:1533-6. https://doi.org/10. 1093/jac/dku009.

74. Alanio A, Denis B, Hamane S, Raffoux E, de la Tour Peffault R, Touratier S, et al. New therapeutic strategies for invasive aspergillosis in the era of azole resistance: How should the prevalence of azole resistance be defined? J Antimicrob Chemother. 2016;71: 2075-8. https://doi.org/10.1093/jac/dkw036.

75. Steinmann J, Hamprecht A, Vehreschild MJGT, Cornely OA, Buchheidt D, Spiess B, et al. Emergence of azole-resistant invasive aspergillosis in HSCT recipients in Germany. J Antimicrob Chemother. 2014;70:1522-6. https://doi.org/10.1093/jac/dku566.

76. Bueid A, Howard SJ, Moore CB, Richardson MD, Harrison E, Bowyer P, et al. Azole antifungal resistance in Aspergillus fumigatus: 2008 and 2009. J Antimicrob Chemother. 2010;65: 2116-8. https://doi.org/10.1093/jac/dkq279.

77. Fuhren J, Voskuil WS, Boel CHE, Haas PJA, Hagen F, Meis JF, et al. High prevalence of azole resistance in Aspergillus fumigatus isolates from high-risk patients. J Antimicrob Chemother. 2015;70:2894-8. https://doi.org/10.1093/jac/dkv177.

78. Escribano P, Peláez T, Munoz P, Bouza E, Guinea J. Is azole resistance in Aspergillus fumigatus a problem in Spain? Antimicrob Agents Chemother. 2013;57:2815-20. https://doi. org/10.1128/AAC.02487-12.

79. Klaassen CHW, de Valk HA, Curfs-Breuker IM, Meis JF. Novel mixed-format real-time PCR assay to detect mutations conferring resistance to triazoles in Aspergillus fumigatus and prevalence of multi-triazole resistance among clinical isolates in the Netherlands. J Antimicrob Chemother. 2010;65:901-5. https:/ doi.org/10.1093/jac/dkq041.

80. Chowdhary A, Sharma C, Kathuria S, Hagen F, Meis JF. Prevalence and mechanism of triazole resistance in Aspergillus fumigatus in a referral chest hospital in Delhi, India and an update of the situation in Asia. Front Microbiol. 2015;6. https://doi.org/ 10.3389/fmicb.2015.00428.

81. Baddley JW, Marr KA, Andes DR, Walsh TJ, Kauffman CA, Kontoyiannis DP, et al. Patterns of susceptibility of Aspergillus isolates recovered from patients enrolled in the transplantassociated infection surveillance network. J Clin Microbiol. 2009;47:3271-5. https://doi.org/10.1128/JCM.00854-09.

82. Kidd SE, Goeman E, Meis JF, Slavin MA, Verweij PE. Multitriazole-resistant Aspergillus fumigatus infections in Australia. Mycoses. 2015;58:350-5. https://doi.org/10.1111/myc.12324.

83. Negri CE, Gonçalves SS, Sousa ACP, Bergamasco MD, Martino MDV, Queiroz-Telles F, et al. Triazole resistance is still not emerging in Aspergillus fumigatus isolates causing invasive aspergillosis in brazilian patients. Antimicrob Agents Chemother. 2017;61. https://doi.org/10.1128/AAC.00608-17.

84. Verweij PE, Lestrade PPA, Melchers WJG, Meis JF. Azole resistance surveillance in Aspergillus fumigatus: beneficial or biased? J Antimicrob Chemother. 2016;71:2079-82. https://doi.org/10. 1093/jac/dkw259.

85. Burgel PR, Baixench MT, Amsellem M, Audureau E, Chapron J, Kanaan R, et al. High prevalence of azole-resistant Aspergillus fumigatus in adults with cystic fibrosis exposed to itraconazole. Antimicrob Agents Chemother. 2012;56:869-74. https://doi.org/ 10.1128/AAC.05077-11.

86. Davel, G.; Canteros, C. [Epidemiological status of mycoses in the Argentine Republic] - PubMed Available online: https://pubmed. ncbi.nlm.nih.gov/17585656/().

87. Dignani MC, Davel G, Refojo N, Mazza M, Córdoba S, Hevia AI, et al. The epidemiology of mould infections in Argentina: Review and experience. Curr Fungal Infect Rep. 2012;6:336-45. https:// doi.org/10.1007/s12281-012-0115-9.

88. Riera, F.O., Caeiro, J.P., Denning, D.W. Burden of serious fungal infections in Argentina. J. Fungi 2018, 4, doi:https://doi.org/10. 3390/jof4020051.

89. Frías-De León MG, Zavala-Ramírez M, Córdoba S, Zúñiga G, Duarte-Escalante E, Pérez-Torres A, et al. Phenotypic characteristics of isolates of Aspergillus section Fumigati from different geographic origins and their relationships with genotypic characteristics. BMC Infect Dis. 2011;11:116. https://doi.org/10.1186/14712334-11-116.

90. Romero, M., Messina, F., Marin, E., Arechavala, A., Depardo, R., Walker, L., Negroni, R., Santiso, G. Antifungal resistance in clinical isolates of Aspergillus spp.: when local epidemiology breaks the norm. J. Fungi 2019, 5, doi:https://doi.org/10.3390/ jof5020041

91. Leonardelli F, Theill L, Nardin ME, Macedo D, Dudiuk C, Mendez E, et al. Primer aislamiento clínico en Sudamérica de una cepa de Aspergillus fumigatus resistente a itraconazol con la sustitución G54E en Cyp51Ap. Rev Iberoam Micol. 2017;34:468. https://doi.org/10.1016/j.riam.2016.05.005.

92. Isla G, Leonardelli F, Tiraboschi IN, Refojo N, Hevia A, Vivot W, et al. First clinical isolation of an azole-resistant Aspergillus fumigatus isolate harboring a TR46 Y121F T289A mutation in South America. Antimicrob Agents Chemother. 2018;62. https:// doi.org/10.1128/AAC.00872-18.

93. Hermida-Alava K, Brito Devoto T, Sautua F, Gordó M, Scandiani $\mathrm{M}$, Formento N, et al. Antifungal susceptibility profile and molecular identification of Cyp51C mutations in clinical and environmental isolates of Aspergillus flavus from Argentina. Mycoses. 2020;64:95-101. https://doi.org/10.1111/myc.13193.

94. Le Pape P, Lavergne RA, Morio F, Alvarez-Moreno C. Multiple fungicide-driven alterations in azole-resistant Aspergillus fumigatus, Colombia, 2015. Emerg Infect Dis. 2016;22:156-7.

95. Alvarez-Moreno C, Lavergne RA, Hagen F, Morio F, Meis JF, Le Pape P. Fungicide-driven alterations in azole-resistant Aspergillus fumigatus are related to vegetable crops in Colombia, South America. Mycologia. 2019;111:217-24. https://doi.org/10.1080/ 00275514.2018 .1557796$.

96. Hagiwara, D., Watanabe, A., Kamei, K., Goldman, G.H. Epidemiological and genomic landscape of azole resistance mechanisms in Aspergillus fungi. Front. Microbiol. 2016, 7.

97. Montenegro G, Puch SS, Jewtuchowicz VM, Pinoni MV, Relloso $\mathrm{S}$, Temporitti E, et al. Phenotypic and genotypic characterization of Aspergillus lentulus and Aspergillus fumigatus isolates in a patient with probable invasive aspergillosis. J Med Microbiol. 2009;58:391-5. https://doi.org/10.1099/jmm.0.005942-0.

98. Giusiano GE, Piontelli E, Fernández MS, Mangiaterra ML, Cattana ME, Kocsubé S, et al. Biodiversity of species of Aspergillus section Fumigati in semi-desert soils in Argentina. 
Rev Argent Microbiol. 2017;49:247-54. https://doi.org/10.1016/ j.ram.2017.02.002.

99. de Azevedo Bastos VR, de Castro Lima Santos DW, Padovan ACB, Melo ASA, de Abreu Mazzolin M, Camargo LFA, et al. Early invasive pulmonary aspergillosis in a kidney transplant recipient caused by Aspergillus lentulus: First Brazilian Report. Mycopathologia. 2015;179:299-305. https://doi.org/10.1007/ s11046-014-9840-7.

100. Pontes L, Beraquet CAG, Arai T, Pigolli GL, Lyra L, Watanabe A, et al. Aspergillus fumigatus clinical isolates carrying CYP51A with TR34/L98H/S297T/F495I substitutions detected after four- year retrospective azole resistance screening in Brazil. Antimicrob Agents Chemother. 2020;64. https://doi.org/10.1128/AAC. 02059-19.

101. Bustamante B, Illescas LR, Posadas A, Campos PE. Azole resistance among clinical isolates of Aspergillus fumigatus in LimaPeru. Med Mycol. 2020;58:54-60. https://doi.org/10.1093/mmy/ myz032.

Publisher's Note Springer Nature remains neutral with regard to jurisdictional claims in published maps and institutional affiliations. 